\title{
Research on the Structure of College Students' Identification Towards University Organizations
}

\author{
Wenzhu Wei ${ }^{1} \&$ Li Chen $^{1}$ \\ ${ }^{1}$ School of Education Science, Sichuan Normal University, Chengdu, China \\ Correspondence: Li Chen, Professor, School of Education, Sichuan Normal University, Chengdu 610066, \\ Sichuan, China.
}

Received: September 25, 2019

Accepted: October 18, 2019

Online Published: December 14, 2019

doi:10.20849/jed.v3i3.681

URL: https://doi.org/10.20849/jed.v3i3.681

Fund Item: "Study on the innovative Model of learning space in terms of modernization of higher education" in the western Chinese projects of education in 2018 in the "13th Five-Year Plan".

\begin{abstract}
The organizational changes in modern universities have made the relationship between students and universities more and more complex and diverse. It's of great significance to investigate and understand the ways and extent of students' identification towards organizations in universities. It is found through a qualitative research that students' identification towards university organizations mainly includes four aspects: interest identification, value identification, behavior identification and emotional identification, which are realized through eight paths: organizational attraction, individual subjectivity, consistency between individuals and organization, organizational participation, conformity, a harmonious interpersonal relationship, sense of belonging and identity perception.
\end{abstract}

Keywords: college students, organizational identification, educational management

Chinese Library Classification Number: G64; Document Code: A

\section{Research Background: Relationships Between Students and Universities Changed as a Result of Organizational Transformation in Universities}

Modern universities have become "an evolving ecological system with amazing complexity, extremely diversified and mutually dependent". The relationships between students and universities also become more and more complex (James Duderstadt, 2005). On one hand, transformation of intellectual form has changed the internal structure of organizations in universities, as a result of which disciplines are more obviously differentiated and refined. In an increasingly complicated topic environment, interdisciplinary and trans-major cooperation and communication has been more and more intricate (Chen, X., 1991). Accordingly, students have more diversified ways to participate in organizational activities of universities. On the other hand, development of modern information and technology is an impetus for students' organizations to develop towards flattening and virtualization. As a result, coherence between students and universities drops off and the perceptional approaches and interactive modes between students and universities present significant changes along with changes in both internal and external communication and exchange mechanisms of university organizations.

Under a changing historical background, an investigation and understanding of the structure of college students' recognition and identification of university organizations helps to have an idea about college students' developmental characteristics and the relationships between students and university organizations. All this, in turn, is helpful for universities to improve their educational management strategies.

\section{Research Design and Research Approach}

\subsection{Theoretical Foundation}

The concept of organizational identification has evolved based on the concept of identification. In the 1950s, Freud, for the first time, put forward the concept of identification. According to Freud, identification was a psychological process, an original form which connected emotion between an individual and the others (Chen, L., 2007). The researchers then were inclined to consider the identification process as a psychological process which 
involved a certain kind of interaction between an individual and the others or organizations. By the middle and later periods of $1980 \mathrm{~s}$, the concept of organizational identification stepped into a rapid development period. Organizational identification was deemed as a particular manifestation pattern of social identification. It was not only confined to the psychological process of an individual, but also covered the behavioral aspects of an individual.

As for the influences of organizational identification on individuals, the current studies conclude the following major aspects.

At first, organizational identification helps an individual to realize his self-definition. For instance, Mael \& Ashforth held the viewpoint that organizational identification was perception of an individual on organizational identity and the individual would define himself in accordance with his own membership identity (Ashforth, B. E., \& Meal, F., 1989). That is, organizational identification could help one to answer "who I am?"

Secondly, organizational identification affects the attitude and behavior of an individual in participating in an organization. For instance, Phinner (1990) held the view that organizational identification included an individual's self definition, the sense of belonging to a group, the positive or negative attitude towards a group and participation of the group (Ashforth, B. E., \& Meal, F., 1989). In a study on state-owned enterprises in China, Wang Yanbin also took the view that an organization member not only had the sense of contract, sense of responsibility, sense of belonging and sense of dependence in the organization, but also conducted corresponding elaborated behavioral outcome manifested on this psychological foundation (Wang, Y., 2004). Tracy Manuel and Petroni Davide Dante(2019) believe that organizational identity is a key factor in organizational life and promotes pro-organizational behavior. Ingil Shulata Sia and Arum Etikaliana Hidayat(2019) argue that organizational identity has a significant impact on job engagement. According to Wiesenfeld \& Raghuram \& Garud, strong organizational identification encouraged the individuals inclined to cooperative organizational behaviors, which, in turn, increased the motivational level required to meet up with organizational requirements and cut down on the quit rate. On the contrary, Scott \& Lane believed that weakened organizational identification would lead to indifference to the organization, declined trust and support in the organization and give rise to excessive focus on the individual and pursuit of personal target. What's worse, weakened organizational identification would even cause an individual to reverse behaviors of an individual to intentionally damage or undermine the organization (Su, X., \& Ge, J., 2007).

How to form and develop organizational identification? Cheney (1983) maintained that organizational identification was manifested as the loyal and harmonious membership relations (Cheney, G., 1983) between an individual and the organization on the basis of similarity between them. That is, similarity and destiny sharing between an individual and the organization was the foundation to form and develop organizational identification.

With regard to conditions for formation of organizational identification, Mael \& Tetrick (1992) insisted that organizational identification included shared features and shared experiences (Mael, F. A., \& Tet rick, L. E., 1992). The significance of external organizations proposed by Ashforth (1992) and organizational reputation, influences of family members and evaluation of the public or customers are all critical elements which affect organizational identification. In her study on antecedent variables in organizational identification, Luo Na pointed out, the antecedent variables which affected organizational identification not merely included external elements of the organization, but also included organizational elements (such as, human resource environment within the organization, needs of substance provision, leadership within the organization and cultural types of the organization, etc.) and individual elements (such as, tenure of office, age, orientation of self-concept of an individual and psychological empowerment, etc.) (Luo, N., 2015). Among all the above elements, the similarity and destiny sharing between an individual and the organization pertain to organizational elements in antecedent variables.

To sum up, organizational identification mainly contains the rational cognition of an individual in the consistence between the individual and the organization which is formed under the influences of both internal and external elements of the organization and elements of the individual himself, as well as the sense of responsibility and sense of belonging, which are all manifested as the behavior of supporting the organization. That is, the antecedent variables of "organizational identification" mainly include external elements of the organization, organizational elements and individual elements, whereas post dependent variables mainly include perception of consistence, sense of belonging and sense of responsibility, etc., as well as the behaviors of supporting and maintaining the organization. 


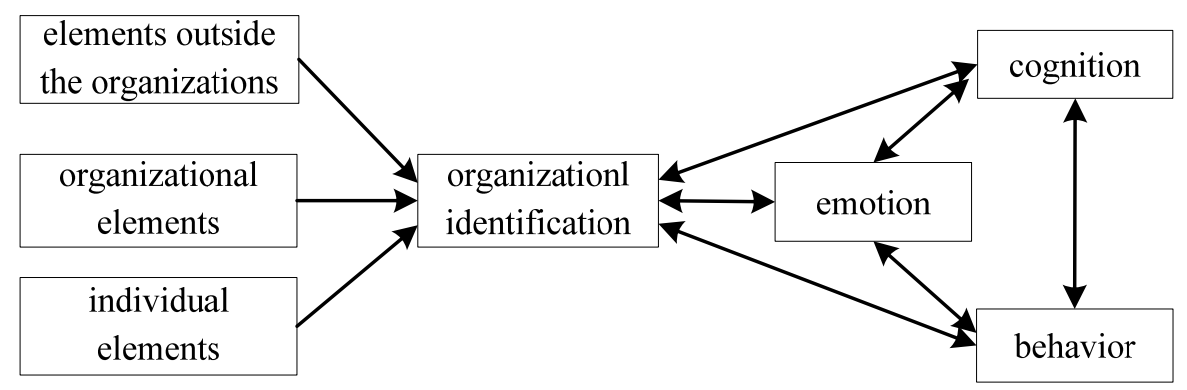

Figure 1. The concept framework of organizational identification

As shown in Figure 1, organizational identification is a dynamic process. It is affected by a variety of elements prior to its formation and in the process of formation. Once formed, it exerts actual influences on individuals and the organizations of the individuals. Then, for a particular group in a particular organization, which aspects does "organizational identification" contain? The current studies mainly focus on corporate organizations, and there have rarely been studies on organizational identification in terms of university organizations.

\subsection{Research Design}

Previous literature reviews are studied to have a general idea of the conceptual framework of organizational identification. On that basis, this research uses the research method of grounded theory and specifically uses methods such as in depth interview and focus group interview to gain data on college students' identification of university organizations. The data obtained are further encoded to explore the structure of college students' organizational identification.

\subsubsection{Research Subjects}

This study uses purposive sampling for in depth interview. When the collected data reach a saturation condition, the process of collecting and analyzing data is over. Altogether, 30 full time students in public universities are chosen as the research subjects. The basic information is shown as in Table 1. The research subjects are not totally the same in terms of school, region, class, major and other aspects. The aim is to find the similarities in universities' organizational identification between students from different levels of schools and different disciplines. Thus, the structure of college students' organizational identification is established which makes the research result applicable nationwide.

Table 1. Basic information of research subjects

\begin{tabular}{cccc}
\hline School & Region & Research subjects (code) & $\begin{array}{c}\text { Academic } \\
\text { discipline }\end{array}$ \\
\hline $\begin{array}{c}\text { Sichuan Normal } \\
\text { University }\end{array}$ & $\begin{array}{c}\text { Southwes } \\
\text { t region }\end{array}$ & $\mathrm{g}, \mathrm{l}, \mathrm{oy}, \mathrm{z}, \mathrm{d}, \mathrm{w}, \mathrm{s}, \mathrm{yx}, \mathrm{t}, \mathrm{y}$ & $\begin{array}{c}\text { pedagogy, } \\
\text { engineering }\end{array}$ \\
$\begin{array}{c}\text { Nanjing } \\
\text { University of }\end{array}$ & & $\mathrm{n}, \mathrm{w}, \mathrm{s}, \mathrm{f}$ & engineering \\
$\begin{array}{c}\text { Aeronautics and } \\
\text { Astronautics } \\
\text { Nanjing }\end{array}$ & $\begin{array}{c}\text { Eastern } \\
\text { China }\end{array}$ & & \\
$\begin{array}{c}\text { University of } \\
\text { Science and } \\
\text { Technology }\end{array}$ & & $\mathrm{lt}, \mathrm{l}$ & \\
Tarim university & $\begin{array}{c}\text { Northwes } \\
\text { t region }\end{array}$ & $\mathrm{lb}, \mathrm{n}, \mathrm{s}, \mathrm{h}$ & agriculture \\
South China & South & $\mathrm{zx}, \mathrm{g}$ & pedagogy \\
Normal & China & & \\
University & & &
\end{tabular}


Changsha

University of

Science and

Technology

Zhongnan

University of

Economics and

Law

Zhengzhou

University

Henan University

of Chinese

Medicine

Shangqiu Normal

University
1

science

$\mathrm{cw}, \mathrm{f}$

economics

Central

China

c, $\mathrm{z}$

engineering

w, h

medical

science

zy

management

science

\subsubsection{Research Route}

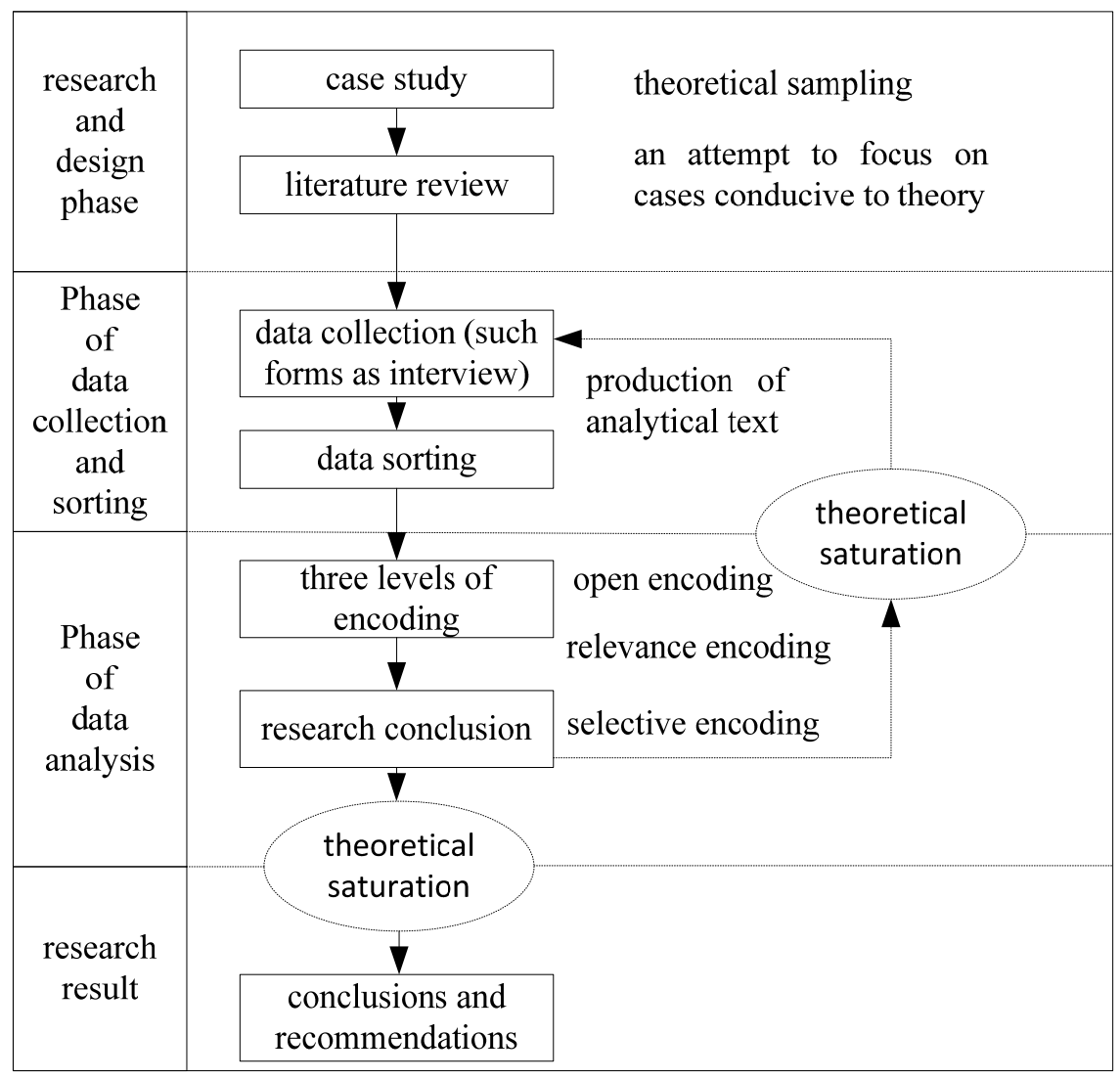

Figure 2. An overall flow chart of the research

As shown in Figure 2, an interview outline took form at the outset of the research by discussion of case studies in combination with literature review. The grounded theory was used in the material which reached its theoretical saturation after three levels of encoding. Finally, a structural model of college students' organizational identification was established. 


\subsubsection{The Analysis Process of Data}

The constructive grounded theory method proposed by Charmaz is used in the data analysis of the research, which altogether includes four encoding processes: initial encoding, focal encoding, axial encoding and theoretical encoding.

Initial encoding refers to layer-by-layer conceptualization and abstraction of the original data (Ma, S., 2009) . This study defines 489 label codes by means of encoding, line by line, every event of the original interview material. Then, the study makes classification and integration after constantly seeking common points and finally finds 24 tentative project categories.

Focal encoding is the second phase of the coding. It's not a totally linear process compared with the initial encoding. A continuous comparison of different data gives researchers a clearer train of thought. This study makes further classification and integration of the initial encoding and constantly seeks common points to find out the similarity of college students in organizational identification of universities, colleges, majors, classes, students' unions, associations, dormitories and other organizations. On this basis, the study adopts Delphi Method by inviting three postgraduate students majoring in pedagogy to discuss together and deliberate repeatedly and finally reach a consensus. Altogether 14 focal encodings in college students' organizational identification are obtained (identity perception, certainty, interpersonal trust, organizational convenience, participation, autonomy of an individual, realization of values, sense of belonging, organizational charm, sense of pride, consensus between an individual and an organization, similarity between organization members, subjectivity of an individual and conformity).

Axial encoding is a process in which categories are pointed to sub-categories, which makes both the property and dimension of categories more concretized. Data split by the researchers at the outset of initial encoding is realigned and a sort of consistency is given to the generated analysis (Liu, H., 2012). When answering such questions as "where, why, who, how and how does it come out", axial encoding answers has its own set of scientific terms to construct the relations between visible categories. Axial encoding makes focal encoding return again to the original material and set up corresponding relations with the original material so as to ensure validity of encoding. As shown in Figure 3, after the 14 concepts of focal encoding return to the original material, altogether 8 core concepts of organizational identification are obtained, namely, organizational participation, conformity, consistence between an individual and an organization, harmonious interpersonal relationship, sense of belonging, perception of identity, organizational attraction and subjectivity of an individual. A further review of the 8 core concepts can classify them into the four aspects of behavior identification, interest identification, value identification and emotional identification. Among them, emotional identification includes interpersonal identification and identification of belonging. Besides, behavior identification, interest identification, value identification and emotional identification parallel with each other. 


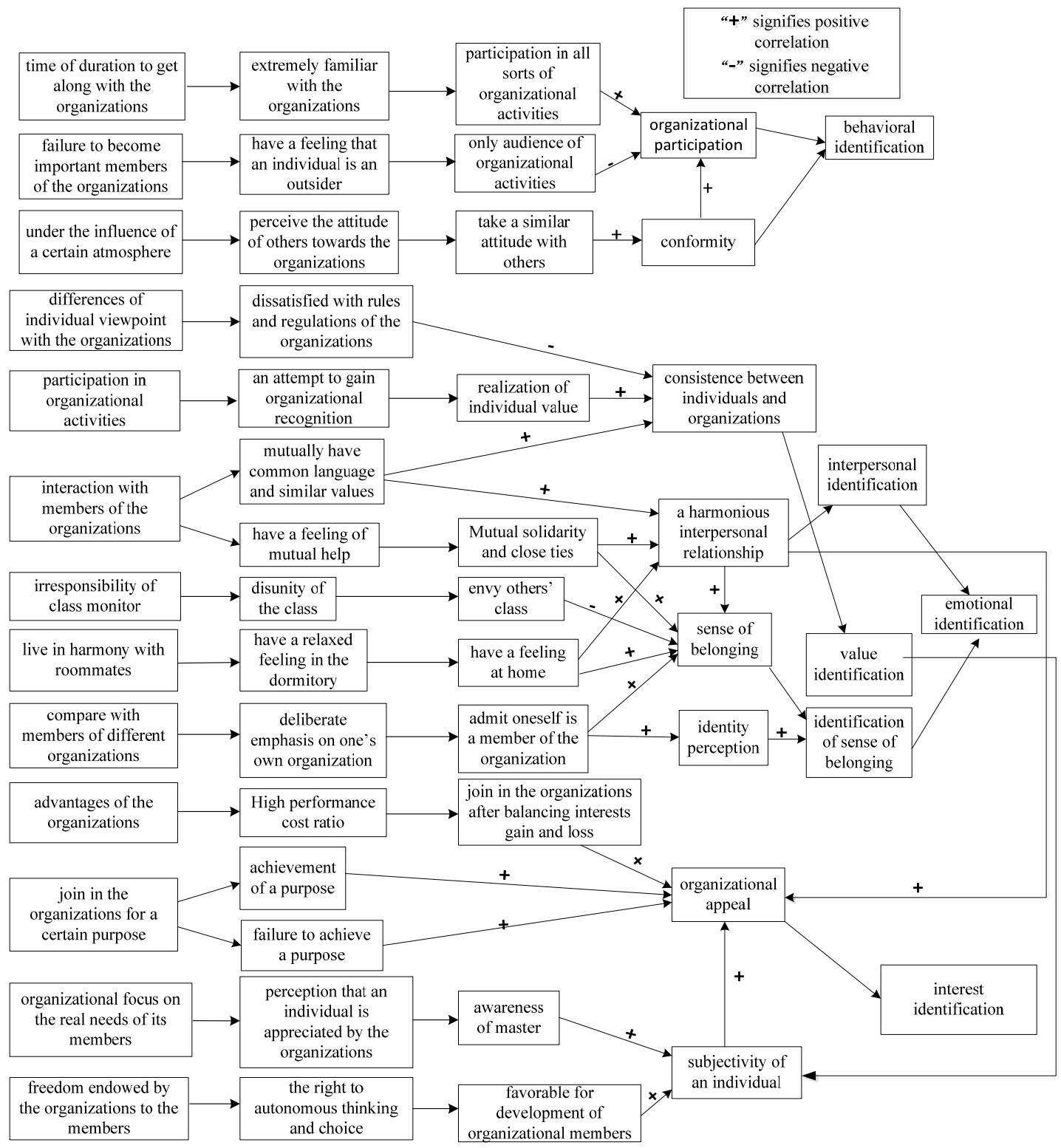

Figure 3. Axial encoding

Theoretical encoding refers to encoding at a complex level which is processed with code selection in the process of axial encoding (Sun, J., \& Jiang, K., 2009). The function of theoretical encoding is to make the relations between categories formed in the process of axial encoding more concretized. With reference to the four aspects of organizational identification of college students gained in axial encoding, this study constructs a structural model of organizational identification among university students as shown in Figure 4. 


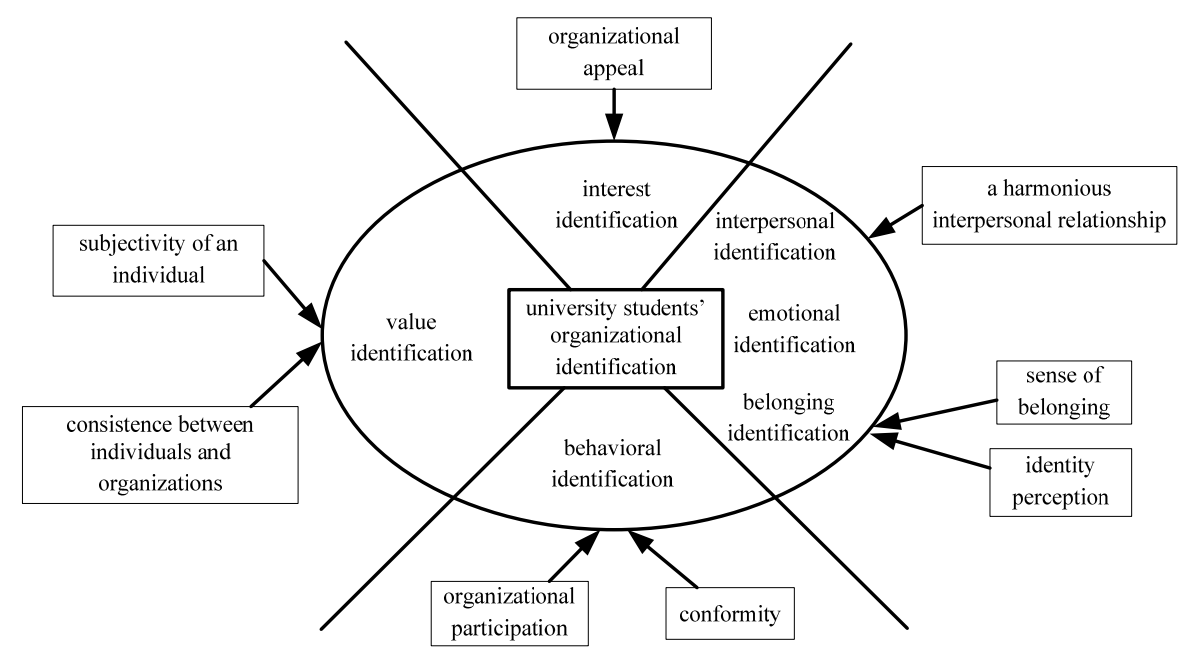

Figure 4. Theoretical encoding: structural model of college students' organizational identification

This study uses the grounded theory method to make an analysis of the similarities between organizational identification of university students and constructs a structure of the organizational identification. The structure mainly includes the four aspects of interest identification, value identification, behavior identification and emotional identification which are realized by means of 8 routes, namely, organizational attraction, subjectivity of an individual, consistence between an individual and an organization, organizational participation, conformity, identity perception, sense of belonging and harmonious interpersonal relationship. Although the model constructed in this study is universal, it does not necessarily mean each individual has the same identification towards university organizations. Thus, an analysis of college students' organizational identification structure helps to have an idea about possible characteristics of contemporary university students in their identification towards university organizations.

\section{Characteristics of Current College Students' Organizational Identification}

\subsection{Interest Identification Based on "Exchange Principle"}

It is known from an analysis of the investigation, the interest identification of college students' organizational identification is realized by means of the route of "organizational attraction", whereas organizational attraction originates from "organizational charm" and "organizational convenience".

A review of the original material ascertains that "organizational charm" is derived from the schools' social reputation, faculty power, curriculum offered, quality of teaching, social recognition, climate of learning, infrastructure and so on. In a word, university students usually have higher sense of identification towards those organizations which are capable of satisfying both the spiritual needs (knowledge learning, self-esteem and respect, cultural edification, etc.) and the material needs of the research subjects.

"Organizational convenience" mainly means university organizations provide students with convenient conditions for their learning, life and work in the future. In other words, when students participate in the organizations, they can get access to maximum benefits, their needs get satisfied and, as members of the organizations, they are able to enjoy the opportunities and resources that are not available to others. All these conveniences become the emotional foundation for university students' identification towards these organizations after a rational comparison.

The formation mechanism of the organizational identification based on "interest exchange" is as follows: positive stimulus of university organizations" - contribution and retribution of university students. While the conveniences provided by university organizations satisfy the material needs of university students (for example, pretty campus environment, favorable hardware facilities and lower consumption level), they believe it must be "cost-effective" and "well worth" to choose this university. While the conveniences provided by university organizations satisfy the spiritual needs of university students (for example, pursuit of knowledge and need of self-esteem, etc.), they are willing to show preference to their university organizations from the depth of their heart".

In brief, university students who lay emphasis on interest identification attach greater importance to their universities' capability of satisfying their needs. The more their universities satisfy the material needs and 
spiritual needs of the students, the higher identification the students have towards their university students.

\subsection{Value Identification With Co-existence of Subjectivity and Consistency}

An analysis of the structural model of identification finds that the value identification in college students' organizational identification primarily refers to identification of values and objectives of striving. Value identification can be further classified into the two concepts of "subjectivity of an individual" and "consistence between an individual and an organization".

"Subjectivity of an individual" is a particular subordinate concept in the structure of college students' organizational identification and has not yet been mentioned in previous studies on organizational identification. "Respect of students' subjectivity" is not a newly proposed statement. The learning theory of humanism emphasizes that teaching is centered with students and teachers are no longer the authority, but merely play a role as catalyst or midwife. "World Declaration on Higher Education for the Twenty-First Century: Vision and Action" at the educational conference of world higher education held in 1988 declared that "In the current ever-changing world, it is obvious that higher education is supposed to have a new perspective and a new model which is centered with students" (Liu, Y., 2014). With reform and development of higher education, student management in Chinese universities has begun to pursue the value concept of "human orientation". Nonetheless, ideal and actual contradictions are still inevitable in reality and the issue of loss of students' subjectivity still exists in student management in the universities.

"Subjectivity of an individual" in this study mainly means that university students are entitled to organize activities in a rational way on their own. They are not willing to just become appendages of the organizations. Furthermore, they strive for a dominant position to enable the organizations to focus more on their feelings and take more consideration of their real needs, finally realizing human orientation. If university students have no dominant position in the organizations and have no feeling of space for personal development, then there is no way to talk about identification. If university management still employs "bureaucratic and panoramic monitoring" and externally constrains students by a compulsory means and with a management system of stereotyped evaluation standards, there is no way to talk about identification for students. Therefore, "individual subjectivity" of college students should be regarded as an important part of organizational identification of university students.

"Consistence between an individual and an organization" in this study mainly means that the way of behaving, interpersonal concept and value attitude of university students are similar with the organizations they join. This concept includes the two parts of "realization of value" and "consistency of value". "Realization of value" means that university students show their capacity in the process of participating in organizational activities and enhance their self-efficacy. "Consistency of value" means that the values of organizations and individuals are matched. It is emphasized in Sun Zi Bing Fa that "victory comes when the team and the leadership do share the same goals". What is implied in this saying is that great power comes when the objectives of all members at all levels in the organization are consistent. When the organization has the same objective with its individual members, the emotional appeal of the organization to its members is huge, and, likewise, the individuals may have greater trust in the organization. On the contrary, the students would refuse to define themselves in line with the identity of the organization.

\subsection{Behavioral Expressions of "Participation" and "Conformity"}

According to the social cognitive theory, the social cognition of an individual is the foundation of his social behaviors. In the process of socialization, the cognitive structure of the individual is ceaselessly constructed which ultimately form a certain stable cognitive model to recognize himself and others. Under the impelling of this cognitive model, all sorts of social behaviors of the individual come into being (Zou, W., 2013).

It is found in the survey that college students are more included to identify with the organizations they are familiar with and even some students take an active part in construction of the organizations if they believe they are "important members" of the organizations. The more college students identify the organizations, the more active they are in participating in organizational activities. That is to say, "participation" has been a behavioral expression of organizational identification. Otherwise, when the boundary between "student cadre" and student members becomes too distinct in the organization, the enthusiasm of student members in participating in organizational construction might be confined. They may have the wrong idea that "it doesn't matter at all without me" and have no awareness of "master". Thus, they show lower organizational identification.

"Conformity behavior" implies that individuals of the organizations consciously or unconsciously make similar response with other organizational members in terms of words and deeds under the influence or pressure of others and under a particular circumstance. In this research, part of students show that they would "follow suit" 
to run for secretaries of students union or have high sense of self-pride in their university during the anniversary under the influence of the atmosphere. All the above are behaviors of organizational identification under the psychology of conformity.

The self-classification theory and Giddens' self-identification theory are two major theoretical frameworks to interpret the conformity behavior. Self-classification theory is a process in which a collective phenomenon and an individual's social cognition combine with each other after the individual actively psychologizes the group ( $\mathrm{Li}$, C., \& Gong, X., 2006). Stability of an individual's selfness concept will affect the individual's perception of himself which, in turn, helps the individual to accurately predict his behavior. An individual with stronger sense of self-identification may make accurate prediction on his own behavior instead of blindly imitating behaviors of the group. Therefore, the conformity behavior of students' organizational identification, in the final analysis, implies instability of the selfness concept. Lower self-identification and lack of the capacity of make an accurate prediction on their own behaviors ultimately give rise to unquestioning organizational identification.

\subsection{Emotional Identification Under the Influences of Identity Perception, Interpersonal Relationship and Sense of Belonging}

The emotional identification of the structure of university students' organizational identification mainly refers to the psychological connection of university students and university organizations in terms of emotion. It more expresses students' emotional dependence upon the organizations. According to the social identification theory, an individual shows identification towards his group through social classification so $s$ to shape common values and emotion and have internal preference and external preference (Gong, S., 2015). The "emotional identification dimensionality" in organizational identification of university students includes the three aspects of "harmonious interpersonal relationship", "sense of belonging" and "identity perception". In this study, "identity perception", "harmonious interpersonal relationship" and "sense of belonging" are paralleled causal relationships. At first, university students ought to perceive their organizational identity. At the time when they recognize their organizational identity, they also have a sense of belonging to the organization. In the process of interaction with other organizational members, they help each other and set up a harmonious interpersonal relationship. Likewise, a harmonious relationship helps university students to have a sense of belonging to the organization.

As a significant indicator in evaluating the relationship between university students and organizations, the degree of identity perception has a direct effect upon the behavioral manifestation of university students. Those with higher identity perception are able to perceive the importance of university organizations to themselves and, therefore, will make great efforts to conduct behaviors that conform to the organizational identity and do benefit to the organization.

Marx said, production of human being couldn't go without association between humans. Mayo believed that human was "social man", so they did not purely pursue material and money, but such social and psychological needs as friendship, sense of security and sense of appendage (Mayo, G. E., 1963). As a member of university organizations, ever since his entrance to the campus, a university student is brought into a system of network embraced by all kinds of social relationships. His roles take change in accordance with different interpersonal relationships, as he is the center of all kinds of relationships of schoolmates, relationships of teachers and students, relationships of leaders and being led. When university students feel satisfied with the interpersonal relationships among organizational members, they may work together in an effective and cooperative way and take an initiative to classify themselves as a member of the organization. This, to some extent, is a feeling of "everyone in the organization behaves as a family member". Each member identifies his organizational identity.

The concept of "sense of belonging" is generated in this study which keeps consistent with previous researchers. For example, Xu Weiling, Zheng Boxun (2002) (Xu, W., \& Zheng, B., 2002), Wei Jun et al. (2007) (Wei, J., Chen, Z., \& Zhang, M., 2007), Tajfel \& Pratt (1998) (Lu, H., 2010) also emphasized that the sense of belonging was an important concept when they defined organizational identification. The "sense of belonging" in university students' organizational identification means that university students have a feeling of "home" towards the organizations. They regard the organizations as a sheltered harbor, which is a kind of active emotional recognition.

\section{Developmental Characteristics of University Students From the Perspective of Organizational Identification Structure}

\subsection{Organizational Identification of College Students Are Based on Interest Exchange}

As previous mentioned, the aspect of interest in college students' organizational identification is embodied in "organizational attraction", whereas organizational attraction originates from "organizational charm" and 
organizational convenience". In other words, when university organizations meet both the material needs and spiritual needs of students, their identification towards the organizations will increase accordingly.

According to the principle of social exchange proposed by the sociologist Homans, the nature of interpersonal communication is a process of social exchange. This process is not necessarily a physical process, but must be utilitarian which has more gain than loss (Tan, D., 2006). Meanwhile, Max Abbott ever analyzed school organizations according to the theory proposed by Weber and he summarized that "Obviously, school organizations are a highly developed bureaucratic organization" (Zhang, X., 2001). The hypothesis about an individual lies behind his view that man is regarded as "a rational economic man" and all behaviors of man are, to the hilt, to satisfy himself and gain profits (Pu, R., 2001). In this study, only when university students are satisfied with the organizations in terms of their interest pursuit, can they conduct behaviors favorable for the organizations. This indicates that university students' identification towards the organizations is utilitarian. If the universities seek out to acquire higher identification from the students, it is a must for them to try all means to satisfy the interest needs of the students.

\subsection{College Students Pursue a Dominant Position in the Organizations}

In this study, value identification in the organizational identification of university students includes "subjectivity of an individual" and the term "enforce" is repeatedly mentioned. For instance, "The college enforces us to register with yiban.cn", "The college enforces its students to get engaged in physical activities", "In my view, everyone should take part in meaningful activities by their own volition instead of being enforced to participate. The forms of the activities should have novelty instead of all being in the same key", etc. Generally speaking, all university students have the intention to strive for their own dominant position in the organizations.

"Subjectivity" is not a new term as it is one of the essential characteristics of students. The traditional viewpoint of ontology lays emphasis on teachers' authority and "knowledge-based egoism", disregarding subjectivity of students in education and communication of students' ideas. Therefore, the negative effects are apparent. With evolving of the theory of humanistic learning, Rodgers put forward the "student-centered teaching concept". In his concept, students are noticed in the process of education, whereas teachers and administrators are no longer authority, but just play the role of a "catalyst" or "midwife". Furthermore, students are no longer passive processing objects and are supposed to give full play to their subjective initiative. In the modern teaching system, subjectivity of college students is manifested in three traits: autonomy, initiative and creativity. Autonomy implies that students, as a subject, are able to make their own decisions and take charge of themselves in the process of education and teaching. Initiative implies that students, as a subject, are able to take the initiative in activities of perceiving time of their own free will. Creativity implies that students, as a subject, are able to take part in creative activities. Without subjectivity, there is no way to mention identification and creativity. Pursuit of students in their position in the organizations conforms to the characteristics of development of the times and students. It is also necessary for university administrators to "see the students", entitle them to make their own decisions, take charge of themselves and transit from heteronomy to self-discipline.

\subsection{College Students Show More Identification Towards Those Organizations With Matched Values}

"Consistence between an individual and the organizations" means that students are similar with the organizations in terms of the way of behaving, interpersonal concepts and values and attitudes. This does not only mean that students exhibit their capacity and enhance their self-efficacy through organizational activities, but also include the value matching between individuals and the organizations. When students believe their values are matched with an organization, they are more likely to recognize the organization. For instance, in the interview, some students mention that "they don't want to take part in the organizations of student union, because 'the bureaucratic atmosphere is too severe"". Also, some other students hold the viewpoint that "the colleges lay much more emphasis on the scientific and research capacity of teachers than their capacity of teaching, while students are in much need of knowledge. Thus, the concepts of the two sides are totally different, which makes it difficult to approve the practice of the colleges". In brief, the more the values of students and organizations are matched, the more the students show identification towards the organizations.

Usually, values have the three manifestation patterns, including interest, need and ideal. Interest is the elementary form of values and an inner measure for an individual to make evaluation. Faith is the core level of values, which guides the thinking and behavior of an individual. Ideal is the manifestation pattern for values to be extended to the future, which is of more appeal (Huang, X., 2007). "Matching of values" implies that the interest, need and ideal of individuals keep consistent with the organizations. Existing studies prove that matching of values is a primary factor that affects employee turnover. Matching of values of individuals and organizations is more likely and effectively to predict the turnover intention of employees than matching of individuals and their jobs. Those employees with more different values are more likely to resign from the 
organizations. On this account, the human resources department of an enterprise integrates values of organizations into the entrance test of its employees with the aim of choosing more stable employees. Likewise, an in-depth understanding of students' values in an indispensable aspect in better management of students in universities.

\subsection{Those College Students With Higher Sense of Organizational Identity Make Greater Efforts to Benefit the Organizations}

The concept of "identity perception" often appears in literature review of western countries. When an individual perceives his organizational membership identity is more prominent than any other identity, he tends to manifest stronger organizational identification (Gao, R., 2011). As a significant indicator in evaluating university students' organizational identification, identity perception has a direct causal relationship with organizational behaviors of students. Those students who show identification towards their organizations are inclined to behave in accordance with their identity and do benefit to the organizations. In the interview, some students say, "When I step out of the campus, I have an obvious feeling that I am a student from A and each gesture and behavior of mine is on behalf of my school". As for university administrators, if they add to the organizational identity sense of students, it is more likely for the students to vindicate the university organizations they take part in.

At the time when university administrators build up the organizational identity sense of students, it should also be noted that part of students may also have a sense of identity without having a total understanding of the situation. Although this kind of identity sense is relatively obscure, ambiguous and situational, it may also give rise to students' blind identification towards the organizations. For instance, some students signify that they might have full sense of self-pride in the university during the school anniversary under the influences of the surrounding atmosphere. University administrators may organize a variety of campus activities and make the best of students' "conformity psychology" to reinforce the organizational identity sense of students and, furthermore, strengthen students' beneficial behaviors to vindicate the organizations.

\subsection{The More Participation, the More Identification, and the More Identification, the More Participation}

The aspect of "behavioral identification" in the structure of students' organizational identification incorporates the concept of "organizational participation". It mainly implies if students believe they are "important members" of the organizations, they are likely to enhance their identification towards the organizations and, furthermore, take active participation in construction of the organizations and other organizational activities. In return, this expedites members' sense of organizational identification. In this study, some students say, "I will have higher sense of identification towards the club when I participate much in club activities as more contributions give me more sense of belonging". On the contrary, some other students say, "I am not a class cadre and have no strong sense of belonging to the class. If I could make some contribution to the class construction, my feeling towards the class will be better".

"Hawthorne effect" advocated in business administration can verify the above viewpoint. When immense changes take place in terms of spirit of corporate employees and they have the sense of participation, they may feel they are appreciated. Therefore, they may amplify their efforts to work, which improves production efficiency. "Democratic management model for students" advocated in pedagogy can also explain the relationship between the sense of participation and organizational identification. It implies that each student is encouraged to take part in organizational affairs in the form of "joint participation and equal communication" with the aim of giving full play to the participant and shaping the active developmental motive and capacity. In that way, the students will, up to the hilt, give play to their potential in organizational construction (Pang, S., 2015).

Based on this, it is necessary for university administrators to avoid overemphasizing the functions of student cadres in organizational construction and neglect contributions of the group of common students. Otherwise, the group of common students may reduce their organizational identification towards the organizations as a result of weakened sense of participation.

\subsection{The Degree of Interpersonal Relationship Is One of Indicators to Judge Whether College Students Show Identification Towards the Organizations}

The aspect of "emotional identification" in the structure of college students' organizational identification constructed in this study not only includes "sense of belonging" and "identity perception", but also includes "harmonious interpersonal relationship". It is found through the study that the college students are inclined to show identification towards an organization with benign emotional network. Some students affirmatively disclose that their identification towards their dormitory or class is based on the friendly emotion with their roommates or classmates. When some graduates recall their university life, what they bear in mind is still the good feeling of mutual help among roommates. 
Fei Xiaotong (Fei, X., 2006) came up with the pattern of difference sequence. He signified that the traditional Chinese social structure was a corrugated difference sequence of concentric circle. He was the center of the corrugation and his relationship with other people was just like the corrugation in the water which was pushed out one circle after another, further and further and thinner and thinner, and shaped a difference sequence relation with different affinities. In the pattern of different sequence, an individual is the center and all other people rotate across the individual. The closer the distance is, the more intimate the interpersonal relationship is. Influenced by the Confucian culture, Chinese people have peculiar comprehension on interpersonal cooperation and reciprocity, a family-like generic collective orientation and the human culture that returns are more than gains. This urges them to have extremely strong demand on a good interpersonal relationship as it has great appeal to them. Generally speaking, employees are willing to stay in enterprises with strong human kindness and good interpersonal relationships. The employees show high corporate loyalty to these enterprises and will make active contributions to the enterprises (Huang, J., 2009). Likewise, when university administrators are involved in organizational management, students would have correspondingly high sense of identification towards the organizations if they attach great importance to construction of interpersonal emotion.

\section{Strategies to Improve Students Educational Management From the Perspective of Organizational Identification}

Through a survey and study on the structure of university students' organizational identification, we have had an idea about the developmental characteristics of university students from the perspective of the structure, which is of great reference to the administration work in universities. Firstly, it is necessary to shape a good image for the universities and to gain identification from the students. The universities may consider gaining students' identification by means of enhancing their social reputation, degree of social identification, cultural deposits, power of teachers and infrastructure and equipment to satisfy students' interests and needs. Secondly, it is necessary to obscure students' cadre identity and mold the master consciousness. The university administrators may consider strengthening students' "master" consciousness, reinforce their sense of organizational identity and build up their enthusiasm in organizational construction by means of obscuring the identity of "cadre" or adopting the pattern of "shifting system". Thirdly, it is necessary to carry out flat management and enlarge the autonomy of students. The structure of flat management is centered with students, in which teachers provide students with high quality teaching and administrators provide teachers with high quality service. Such transfer of high quality service is aimed to guarantee foundation of university students' autonomy (Dong, H., 2012). It is only with autonomy that university students are able to show identification and make creation. Fourthly, it is necessary to take rational advantage of students' conformity psychology and strengthen the cohesive force of the universities. University organizations may make use of the group effect to provide correct guide and assistance for students so as to strengthen the cohesive force of the classes and social clubs and to cultivate students' collectivism and patriotism (Wang, L., 2010).

\section{References}

Ashforth, B. E., \& Meal, F. (1989). Social Identity Theory and Organization. The Academy of Management Review, 14(1), 20-39. https://doi.org/10.5465/amr.1989.4278999

Chen, L. (2007). A Study on Development of Chinese College Students' Organizations ---A Structural Culturism. Wuhan: PhD Thesis, Huazhong University of Science and Technology, p. 55.

Chen, X. (1991). Introduction to Science: Exploration of Disciplinary Development Theory. Shanghai: Shanghai Joint Publishing Press, pp. 47-67.

Cheney, G. (1983). On the various and changing meanings of organizational membership: a field study of organizational identification. Communication Monographs, (50), 342-362. https://doi.org/10.1080/03637758309390174

Dong, H. (2012). Inspiration and Reference of Flat Management Theory in the Structural Reform of Organizations in Chinese Universities. China Educational Technology, (11).

Duderstadt, J. (2005). A University for the 21st Century. Peking University Press, p. 44.

Fei, X. (2006). Rural China. Shanghai: Shanghai People's Publishing House.

Gao, R. (2011). Differences of the Influences upon Employee Performance between Organizational Identification Based on a Cognitive Perspective and Organizational Commitment Based on an Emotional Perspective. Modern Management Science, (10), 39.

Gong, S. (2015). Study on the Mechanism of Functions of Knowledge-Based Employees' Self-Identity on Organizational Behaviors in a New Generation. PhD Thesis, Xi'an: Northwestern Polytechnical University, p. 20. 
Huang, J. (2009). A Study on Capitalization of Interpersonal Relationships Inside Enterprises. PhD Thesis, Wuhan: Huazhong Agricultural University, p. 20

Huang, X. (2007). Introduction to Psychology. Beijing: People's Education Press, pp. 182-185.

Li, C., \& Gong, X. (2006). Summary of Self-categorization Theory. Journal of Shandong Normal University, (3), 157-159.

Liu, H. (2012). The Microscopic Mechanism of the Intangible Cultural Heritage Protection under the Perspective of Human Capital. Master Thesis, Chengdu: Sichuan Normal University.

Liu, Y. (2014). Rational Thinking of Establishment of Student Status Management in Higher Vocational Colleges --- A Perspective Based on Students' Subjective Development. Modern Education Science (Higher Education Research), (5), 108.

Lu, H. (2010). A Study on Influences of Corporate Culture on Organizational Identification of Employees. Master Thesis, Zhenjiang: Jiangsu University, p. 16.

Luo, N. (2015). A Summary of Progress on the Study of Antecedent Variables in Organizational Identification. Jiangsu Commercial Forum, (4), 62-63.

Ma, S. (2009). The Study of Grounded Theory in Preschool Teachers' Qualitative Research. Master Thesis, Xining: Qinghai Normal University, p. 33.

Mael, F. A., \& Tet rick, L. E. (1992). Identifying Organizational Identification. Educational and Psychological Measurement, 52(4). https://doi.org/10.1177/0013164492052004002

Manuel, T., Dante, P. D., Massimiliano, B., Amata, G. V., \& Stefano, P. (2019). Ethical Climate(s), Organizational Identification, and Employees' Behavior. Frontiers in Psychology, 1356.

Mayo, G. E. (1963). The Social Problems of an Industrial Civilization, translated by Fei, Xiaotong. Beijing: The Commercial Press, p. 87.

Pang, S. (2015). Foundation of Education Science. Beijing: Peking University Press, p.210.

$\mathrm{Pu}, \mathrm{R}$. (2001). Principles of Education Science. Wuhan: Wuhan University Press, p. 291

$\mathrm{Su}, \mathrm{X} .$, \& Ge, J. (2007). Review and Prospect of Research on the Theory of Organizational Identification. Nanjing Business Review, (12), 31.

Sun, J., \& Jiang, K. (2009). Structure of Organizational Identification under the Chinese Background --- An Explorative Study. Sociological Study, (1), 202.

Sya, I. S., \& Hidayat, A. E. (2019). A Virtuous Company Makes Me Engage. The Mediation Role of Organizational Identification in the Workplace. Atlantis: Atlantis Press, p. 263.

Tan, D. (2006). Psychology of Higher Education. Nanjing: Hohai University Press, p. 230.

Wang, L. (2010). A Study on Conformity Based on Organizational Theories. Journal of Chengde Teachers College for Nationalities, (3), 45.

Wang, Y. (2004). Organizational Identification in Management --- Theoretical Construction and an Empirical Analysis of Chinese State-Owned Enterprises During the Transformation Period. Beijing: People's Publishing House, p. 88.

Wei, J., Chen, Z., \& Zhang, M. (2007). Basic Theory, Measurement and Relevant Variables of Organizational Identification. Advances in Psychological Science, (6), 948-955.

Xu, W., \& Zheng, B. (2002). Organizational Identification: A Preliminary and Explorative Analysis of Theories and Essence. Sun Yat-Sen Management Review, (10), 89.

Zhang, X. (2001). The Paradigm Theory of Educational Organizations. Nanjing: Jiangsu Education Publishing House, pp. 57-58.

Zou, W. (2013). Research on the organizational citizenship behavior of College Students. PhD Thesis, Dalian: Liaoning Normal University, p. 12.

\section{Copyrights}

Copyright for this article is retained by the author(s), with first publication rights granted to the journal.

This is an open-access article distributed under the terms and conditions of the Creative Commons Attribution license (http://creativecommons.org/licenses/by/4.0/). 